\title{
Analisis Pengaruh Kualitas Pelayanan, Harga, dan Brand Image Terhadap Kepuasan Konsumen Restoran Pizza Hut Cabang Jember
}

\author{
(Analysis of The Influence of Service Quality, Price, and Brand Image on Customer \\ Satisfaction of Pizza Hut Restaurant Jember Branch)
}

\author{
Tyas Kurniawati* Bambang Irawan, Adi Prasodjo \\ Jurusan Manajemen, Fakultas Ekonomi dan Bisnis, Universitas Jember (UNEJ) \\ Jln. Kalimantan 37, Jember 68121 \\ E-mail: tyaskurniawati18@gmail.com
}

\begin{abstract}
Abstrak
Penelitian ini bertujuan untuk mengetahui adanya pengaruh dari kualitas pelayanan, harga, dan brand image terhadap kepuasan konsumen restoran Pizza Hut Cabang Jember. Jenis penelitian adalah explanatory research. Populasi penelitian adalah seluruh konsumen Pizza Hut di kota Jember. Teknik pengambilan sampel yang dilakukan pada penelitian ini menggunakan nonprobability dengan teknik purposive sampling dan ditetapkan sebesar 120 responden. Metode analisis data yang digunakan adalah analisis regresi linier berganda dengan pendekatan konfirmatori. Hipotesis penelitian adalah terdapat pengaruh kualitas pelayanan terhadap kepuasan konsumen, terdapat pengaruh harga terhadap kepuasan konsumen, dan terdapat pengaruh brand image terhadap kepuasan konsumen restoran Pizza Hut Cabang Jember. Hasil penelitian ini adalah kualitas pelayanan berpengaruh terhadap kepuasan konsumen. Hal ini dikarenakan layanan yang diberikan pihak Pizza Hut Cabang Jember sesuai dengan harapan dan layanan yang diberikan sudah cukup (memuaskan). Maka dari itu, semakin tinggi kualitas layanan maka kepuasan pelanggan juga semakin meningkat. Harga tidak berpengaruh terhadap kepuasan konsumen. Hal ini dikarenakan harga yang diukur dalam penerimaan dan kewajaran harga tidak sesuai dengan yang ditetapkan oleh pihak restoran Pizza Hut Cabang Jember. Brand image tidak berpengaruh terhadap kepuasan konsumen. Hal ini dikarenakan brand image yang dimiliki Pizza Hut Cabang Jember tidak mempunyai pengaruh ke arah positif maupun negatif.
\end{abstract}

Kata Kunci: Brand Image, Harga, Kepuasan Konsumen, Kualitas Pelayanan.

\begin{abstract}
This study aims to knowing the influence of service quality, price, and brand image. This study is explanatory research. Population is all Pizza Hut customer Jember branch. The sampling method for this study was doing with nonprobability sampling with purposive sampling technique and it got 120 respondents. Data analysis method is multiple linear regression with confirmatory approach. The hypothesis of research is there was influenced service quality toward customer satisfaction, there was influenced price toward customer saisfaction., and there was influenced of brand image toward customer satisfaction on Pizza Hut Restaurant Jember Branch. The result of study showed up that service quality has influenced customer satisfaction. It indicates that given service by Pizza Hut Restaurant Jember branch according to the customer's hope, and the given service is enough satisfy. In order that, highly service quality will increase customer satisfaction. Price is not influenced customer satisfaction. It cause estimated price in receiving session and normally price is not same as decision from Pizza Hut Jember branch. Brand image is not influenced toward customer satisfaction. It cause brand image which Pizza Hut's got, it has not influenced to positive and negative direction.
\end{abstract}

Keywords: Brand Image, Price, Customer Satisfaction, Service Quality.

\section{Pendahuluan}

Kompetisi bisnis makan cepat saji di Indonesia tampak semakin intens sebagai akibat dari ekspansi yang dilaksanakan oleh produsen makan cepat saji seperti KFC (Kentucky Fried Chicken), CFC (California Fried Chicken), dan Hoka-hoka Bento. Persaingan kualitas pelayanan, harga dan brand image begitu sengit, menuntut para pemasar untuk dapat memberikan kualitas pelayanan yang terbaik, menciptakan brand image yang melekat dalam benak konsumen dan harga yang terjangkau oleh konsumen.

Saat ini, banyak perusahaan yang semakin memahami arti penting dari kepuasan konsumen dan menjalankan strategi guna memberikan kepuasan bagi konsumennya. Kepuasan konsumen merupakan faktor sangat penting bagi keberadaan, keberlangsungan, dan perkembangan perusahaan. Menurut Engel et al. (1990), kepuasan konsumen merupakan evaluasi purnabeli dimana sekurang-kurangnya memberikan hasil (outcome) sama atau melampaui harapan pelanggan. Sedangkan ketidakpuasan timbul apabila hasil yang diperoleh tidak memenuhi harapan pelanggan.

Salah satu faktor yang mempengaruhi kepuasan konsumen adalah kualitas pelayanan. Goetsch dan Davis (1994) mendefinisikan kualitas pelayanan merupakan suatu kondisi dinamis yang berhubungan dengan produk jasa, manusia, proses dan lingkungan yang mampu memenuhi dan atau melebihi harapan konsumen. Faktor kedua yang mempengaruhi kepuasan konsumen adalah harga. Harga adalah jumlah uang (kemungkinan ditimbang beberapa barang) yang dibutuhkan untuk memperoleh beberapa kombinasi sebuah produk dan pelayanan yang menyertainya (Kotler dan Keller, 2007:156). Penelitian yang dilakukan oleh Atmaja (2011) menunjukkan bahwa kewajaran harga tidak

\footnotetext{
* Corresponding author
} 
berpengaruh signifikan terhadap kepuasan pelanggan. Ini artinya kewajaran harga yang diukur melalui harga yang sesuai dengan kualitas layanan, referensi tingkat, penerimaan harga yang ditetapkan dan kewajaran harga yang ditetapkan tidak berpengaruh terhadap kepuasan pelanggan.

Faktor lain yang mempengaruhi kepuasan konsumen adalah brand image. Brand image saat ini sangat diperhatikan oleh konsumen. Konsumen selalu mempertimbangkan brand image yang melekat pada produk-produk yang telah dibeli. Menurut Kotler (2005:201) brand image adalah seperangkat keyakinan, ide, dan kesan yang dimiliki oleh seseorang terhadap suatu merek.

Salah satu perusahaan makanan cepat saji yang memperhatikan faktor kualitas pelayanan, harga, dan brand image untuk meningkatkan kepuasan konsumen adalah Pizza Hut. Dipilihnya Pizza hut sebagai objek penelitian karena perusahaan ini adalah salah satu produsen makanan cepat saji terbesar di dunia, Pizzahut.com melalui Pizzahut.co.id menyebutkan bahwa jumlah restoran pizza hut hampir 12.000 restoran dan kios pengantar ambil ke luar di lebih dari 86 negara. Pizza hut pertama kali dibuka pada tahun 1958 di Wachita, Kansas, Amerika Serikat oleh Dan Carney dan Frank Carney. Pizza hut hadir di Indonesia untuk pertama kalinya pada tahun 1984, dan merupakan restoran pizza pertama di Indonesia.

Masalah yang dihadapi sekarang ini adalah semakin berkembangnya produsen makanan cepat saji yang semakin banyak dengan menawarkan harga-harga yang kompetitif dengan berbagai produk yang bervariatif. Dalam situasi ini, pizza hut berusaha mendapatkan konsumen baru dan mempertahankan konsumen. Menyadari peran penting konsumen dan pengaruh kepuasan konsumen terhadap laba, pizza hut berupaya mencari cara untuk dapat meningkatkan kepuasan konsumen. Hal ini disadari oleh pizza hut yang menjual makanan cepat saji agar memberikan kualitas pelayanan terbaik, memberikan harga yang terjangkau bagi konsumen dan membentuk brand image yang melekat pada konsumen, sehingga akan berdampak secara terus menerus meningkatnya penjualan produknya serta berimbang dengan meningkatnya kepuasan konsumen.

Ditinjau dari kualitas pelayanan, ternyata kualitas pelayanan gerai pizza hut ternyata masih dianggap belum memuaskan. Hal ini dapat diketahui dari banyaknya keluhan dari masyarakat (64.4\%) mengenai kurang cepatnya perusahaan dalam menangani permasalahan konsumen. Selain masalah yang tersebut di atas, ternyata permasalahan yang sering dialami konsumen pizza hut adalah banyaknya keluhan mengenai pelayanan yang lama dalam delivery order siap antar ke rumah. Tujuan pizza hut bukanlah menjual produk sebanyak-banyaknya dan mencapai peringkat teratas diantara produsen makanan cepat saji lainnya, namun tujuannya adalah meningkatkan kepuasan pelanggan, bagaimana pelanggan bisa puas setelah melakukan pembelian produk di pizza hut dan timbul keinginan membeli produk ulang.

Hipotesis pada penelitian ini antara lain terdapat pengaruh kualitas pelayanan terhadap kepuasan konsumen, terdapat pengaruh harga terhadap kepuasan konsumen, dan terdapat pengaruh brand image terhadap kepuasan konsumen restoran Pizza Hut Cabang Jember.
Berdasarkan latar belakang yang telah diuraikan diatas, maka rumusan masalah dari penelitian ini adalah (1) apakah kualitas pelayanan berpengaruh terhadap kepuasan konsumen restoran Pizza Hut Cabang Jember? (2) Apakah harga berpengaruh terhadap kepuasan konsumen restoran Pizza Hut Cabang Jember? (3) Apakah brand image berpengaruh terhadap kepuasan konsumen restoran Pizza Hut Cabang Jember?

Tujuan penelitian ini adalah untuk mengetahui adanya pengaruh dari kualitas pelayanan, harga, dan brand image terhadap kepuasan konsumen restoran Pizza Hut Cabang Jember.

\section{Metode}

\section{Rancangan Penelitian}

Rancangan yang digunakan oleh peneliti ini adalah penelitian confirmatory research. Karena bertujuan untuk mengkonfirmasi teori dan Explanatory research yaitu penelitian yang bertujuan untuk menganalisis hubunganhubungan antara satu variabel dengan variabel lainnya atau bagaimana satu variabel mempengaruhi variabel lainnya.

\section{Jenis dan Sumber Data}

Jenis data yang digunakan dalam penelitian ini adalah kuantitatif, yaitu data yang berbentuk bilangan (skala likert) dan angka (ordinal) yang diolah dan dianalisis menggunakan tehnik perhitungan matematika dan statistik. Sumber data yang digunakan dalam penelitian ini menggunakan sumber data primer. Dalam penelitian ini data primer berupa hasil jawaban responden atas kuesioner yang diajukan. Data primer ini selanjutnya akan diajukan sebagai data input untuk penelitian hipotesis.

\section{Populasi dan Sampel}

Populasi dalam penelitian ini adalah seluruh konsumen Pizza Hut di kota Jember. Teknik pengambilan sampel yang dilakukan pada penelitian ini menggunakan nonprobability dengan teknik purposive sampling dan ditetapkan sebesar 120 sampel.

\section{Metode Analisis Data}

Penelitian ini menggunakan metode analisis regresi linier berganda dengan pendekatan konfirmatori.

\section{Hasil dan Pembahasan}

\section{Hasil}

\section{Karakteristik Responden}

Karakteristik responden digunakan oleh peneliti untuk memberikan informasi mengenai data demografi responden. Berdasarkan hasil pengumpulan data yang dilakukan, diperoleh data responden konsumen Pizza Hut di Kota Jember sebanyak 120 orang. Karakteristik responden menggambarkan tentang komposisi jenis kelamin, penghasilan, dan pekerjaan. Adapun pembagian karakteristiknya adalah sebagai berikut. 
Tabel 1. Karakteristik Responden Berdasarkan Jenis Kelamin

\begin{tabular}{ccc}
\hline Jenis Kelamin & Frekuensi & Persentase \% \\
\hline Laki-laki & 52 & 43 \\
Perempuan & 68 & 57 \\
\hline Jumlah & 120 & 100 \\
\hline
\end{tabular}

Sumber: data primer diolah, 2017.

Berdasarkan Tabel 1 diketahui bahwa jumlah prosentase jenis kelamin laki-laki sebesar $43 \%$, perempuan 57\% dan total $100 \%$. Sehingga dapat diketahui bahwa responden dalam penelitian ini sebagian besar adalah berjenis kelamin perempuan yaitu sebanyak 68 orang dan laki-laki sebesar 52 orang.

Tabel 2. Karakteristik Responden Berdasarkan Penghasilan

\begin{tabular}{ccc}
\hline Penghasilan & Frekuensi & Persentase \% \\
\hline < Rp. 1.000.000,- & 16 & 13 \\
Rp. 1.000.000-Rp. & 62 & 52 \\
2.000.000,- & & \\
> Rp. 2.000.000,- & 42 & 35 \\
\hline Jumlah & 120 & 100 \\
\hline
\end{tabular}

Sumber: data primer diolah, 2017.

Distribusi tingkat penghasilan responden Pizza Hut Cabang Jember pada Tabel 2 menunjukkan bahwa sebanyak 62 orang responden atau $52 \%$ dari total berpenghasilan lebih dari $\mathrm{Rp}$ 1.000 .000 - Rp. 2.000.000,-. Sedangkan angka terendah sebesar $13 \%$ dari total populasi sebanyak 16 orang responden memiliki penghasilan lebih dari $<$ Rp. 1.000.000,--

Tabel 3. Karakteristik Responden Berdasarkan Pekerjaan

\begin{tabular}{ccc}
\hline Pekerjaan & Frekuensi & $\begin{array}{c}\text { Persentase } \\
\%\end{array}$ \\
\hline PNS & 12 & 10 \\
Karyawan Swasta & 21 & 18 \\
Wiraswasta & 64 & 53 \\
Pelajar/Mahasiswa & 19 & 16 \\
TNI/POLRI & 4 & 3 \\
\hline Jumlah & 120 & 100 \\
\hline
\end{tabular}

Sumber: data primer diolah, 2017.

Berdasarkan Pada Tabel 3 ditunjukkan bahwa sebagaian besar responden pada penelitian ini berprofesi sebagai wiraswasta yaitu sebanyak 53\% dari keseluruhan responden. Sedangkan responden yang berprofesi sebagai karyawan swasta 21 orang responden atau $18 \%$, pelajar/ mahasiswa19 orang responden atau $16 \%$, PNS 12 orang atau $10 \%$, dan TNI/ POLRI hanya 4 orang atau 3\%.

\section{Analisis CFA (Confirmatory Factor Analysis)}

\section{Uji Kesesuaian Model (Goodness of Fit Test)}

Pengujian model pada regresi konfirmatori bertujuan untuk melihat kesesuaian model. Hasil pengujian kesesuaian model dalam studi ini disajikan dalam Tabel 4.
Tabel 4. Indeks Kesesuaian Model

\begin{tabular}{cccc}
\hline $\begin{array}{c}\text { Kriteria Fit } \\
\text { Model }\end{array}$ & $\begin{array}{c}\text { Nilai Fit } \\
\text { Model }\end{array}$ & Standar & Keterangan \\
\hline $\begin{array}{c}\mathrm{X}_{2} \text {-chi- } \\
\text { square }\end{array}$ & $\begin{array}{c}\text { Diharapkan } \\
\text { lebih kecil } \\
\text { dari } \mathrm{X}^{2} \text { pada } \\
\mathrm{df}=588\end{array}$ & Baik \\
yaitu 658.094 & \\
Significance & 0,000 & $\geq 0,05$ & Marginal \\
Probability & 0,920 & $\leq 0,08$ & Marginal \\
RMSEA & 0,664 & $\geq 0,90$ & Marginal \\
GFI & 0,919 & $\geq 0,90$ & Baik \\
AGFI & 1,998 & $\leq 2$ atau 3 & Baik \\
CMIN/DF & 0,900 & $\geq 0,90$ & Baik \\
TLI & 0,940 & $\geq 0,90$ & Baik \\
CFI & &
\end{tabular}

Sumber: output goodness of fit, 2017.

Berdasarkan Tabel 4 diketahui bahwa dari delapan kriteria yang digunakan untuk menilai baik atau layak tidaknya suatu model ternyata lima kriteria terpenuhi dan tiga kriteria marginal. Dengan demikian dapat dikatakan model dapat diterima, yang berarti ada kesesuaian antara model dengan data.

\section{Uji Kausalitas}

Tabel 5. Hasil Pengujian Kausalitas

\begin{tabular}{ccccc}
\hline Hipotesis & $\begin{array}{c}\text { Koefisien } \\
\text { Jalur }\end{array}$ & CR & Probabilitas & Keterangan \\
\hline $\mathrm{Y}_{1} \beta \mathrm{X}_{1}$ & 0,325 & 2,910 & 0,004 & $\begin{array}{c}\text { Signifikan } \\
\text { Tidak }\end{array}$ \\
$\mathrm{Y}_{2} \beta \mathrm{X}_{2}$ & $-0,532$ & $-0,936$ & 0,349 & $\begin{array}{c}\text { Signifikan } \\
\text { Tidak }\end{array}$ \\
$\mathrm{Y}_{3} \beta \mathrm{X}_{3}$ & 0,000 & 0,555 & 0,579 & \begin{tabular}{c} 
Signifikan \\
\hline
\end{tabular} \\
\hline
\end{tabular}

Sumber: output uji kausalitas CFA, 2017.

Berdasarkan Tabel 5 interpretasi masing-masing koefisien jalur adalah sebagai berikut.

\section{Hipotesis 1 : Kualitas Layanan Berpengaruh Signifikan Terhadap Kepuasan Konsumen.}

Kualitas layanan berpengaruh signifikan terhadap kepuasan konsumen, yang terlihat dari koefisien jalur dengan positif sebesar 0.325 dengan C.R sebesar 2.910 dan diperoleh probabilitas signifikan (p) nilai dibawah 5\% yaitu 0.004 . Artinya kualitas layanan berpengaruh secara langsung terhadap kepuasan konsumen, yang berarti bahwa jika 
persepsi akan kualitas layanan meningkat, maka akan meningkatkan pula kepuasan konsumen di Pizza Hut cabang Jember, sebaliknya jika persepsi akan kualitas layanan menurun maka akan menurunkan persepsi akan kepuasan konsumen Pizza Hut Jember. Hasil ini menerima hipotesis satu yang berarti kualitas layanan berpengaruh signifikan terhadap kepuasan konsumen Pizza Hut Jember.

\section{Hipotesis 2 : Harga Berpengaruh Signifikan Terhadap Kepuasan Konsumen}

Hasil analisa pada hipotesis kedua mendapatkan hasil bahwa variabel harga tidak berpengaruh dan tidak signifikan terhadap kepuasan konsumen, dari hasil analisa koefisien jalur dengan arah negatif sebesar -0.532 dengan C.R sebesar -0.936 dan diperoleh probabilitas signifikan (p) diatas 5\% yaitu 0.349 . Artinya harga tidak berpengaruh secara langsung pada kepuasan konsumen Pizza Hut cabang Jember, jika persepsi akan hargamenurun maka akan menurunkan persepsi akan kepuasan konsumen. Hasil ini menolak hipotesis kedua yang menyatakan harga berpengaruh signifikan terhadap kepuasan konsumen Pizza Hut Jember.

\section{Hipotesis 3 : Brand Image Berpengaruh Signifikan Terhadap Kepuasan Konsumen.}

Hipotesis ke tiga yang menyatakan brand image berpengaruh terhadap kepuasan konsumen, dari hasil uji kausalitas mendapatkan hasil yang dilihat dari koefisien jalur sebesar 0.000 dengan kata lain tidak ada pengaruh sama sekali dengan C.R sebesar 0.555 dan diperoleh probabilitas signifikan (p) nilai lebih besar dari 5\% yaitu 0.579 . Artinya brand image tidakadaberpengaruh secara langsung sama sekali pada kepuasan konsumen Pizza Hut Jember, yang berarti bahwa jika persepsi akan brand image dapat meningkat, maka akan meningkatkan pula kepuasan konsumen, sebaliknya jika persepsi akan brand image menurun maka akan menurunkan persepsi akan kepuasan konsumen Pizza Hut cabang Jember. Hasil ini menolak hipotesis ketiga yang berarti brand image berpengaruh signifikan terhadap kepuasan konsumen Pizza Hut Jember.

\section{Pembahasan}

Berdasarkan hasil pengujian model (model pengukuran dan model struktural) yang dibuat untuk studi ini (yaitu evaluasi kesesuaian model dengan data) dihasilkan tingkat kesesuain yang layak sehingga model yang dibangun layak digunakan untuk menguji hipotesis kemudian diperoleh hasil uji hipotesis.

\section{Kualitas Pelayanan Berpengaruh Signifikan Terhadap Kepuasan Konsumen}

Dari hasil penelitian dilapangan variabel kualitas pelayanan mempunyai pengaruh terhadap kepuasan konsumen Pizza Hut cabang Jember. Hasil penelitian tersebut sesuai dengan penelitian yang dilakukan oleh Melanesia (2011) yang menyatakan bahwa kualitas layanan mempunyai pengaruh yang signifikan terhadap kepuasan pelanggan. Kedudukan teori dengan hasil penelitian dilapangan menjadi semakin kuat.Hal ini dikarenakan layanan yang diberikan dari pihak Pizza Hut cabang Jember sesuai dengan harapan, jaminan yang diberikan lebih dari cukup, layanan yang diberikan sudah dari cukup (memuaskan), dengan demikian semakin tinggi kualitas layanan maka kepuasan pelanggan juga semakin meningkat. Oleh sebab itu,kualitas pelayanan di restoran pizza hut cabang Jember harus ditingkatkan lagi, dievaluasi secara berkala, minimal harus dipertahankan mengenai kualitas pelayanannya agar konsumen tetap merasa puas dengan pelayanan yang diberikan oleh restoran Pizza Hut cabang Jember.

\section{Harga Berpengaruh Signifikan Terhadap Kepuasan Konsumen}

Dari hasil penelitian dilapangan tidak ada pengaruh dan tidak signifikan dari variabel harga terhadap kepuasan konsumen. Hasil penelitian ini sesuai dengan penelitian yang telah dilakukan oleh Atmaja (2011) menunjukkan bahwa kewajaran harga tidak berpengaruh signifikan terhadap kepuasan pelanggan. Murah atau mahalnya harga suatu produk sangat relatif sifatnya. Ini artinyaharga yang diukur dalampenerimaan dan kewajaran harga tidak sesuai denganyang ditetapkan oleh pihak restoran Pizza Hut cabang Jember. Oleh sebab itu, pihak manajemen dari restoran pizza hutcabang Jember perlu mempertimbangkan atau meninjau kembali mengenai kebijakan-kebijakan dalam penetapan harga agar konsumen merasa dalam penetapan harga sesuai dengan apa diperoleh, serta demi terciptanya kepuasan kosumen karena harga merupakan variabel keputusan paling penting yang harus diambil oleh restoran Pizza Hut cabang Jember.

\section{Brand Image Berpengaruh Signifikan Terhadap Kepuasan Konsumen}

Dari hasil penelitian dilapangan menunjukkan bahwa brand image tidak berpengaruh signifikan terhadap kepuasan konsumen restoran Pizza Hut cabang Jember. Hasil penelitian tersebut sesuai dengan penelitian yang telah dilakukan oleh Yesenia (2014) menunjukkan bahwa brand image tidak berpengaruh terhadap kepuasan pelanggan. Apabila brand image yang dimiliki Pizza Hut cabang Jember ada peningkatan secara positif maka akan berpengaruh terhadap kepuasan konsumen. Sebaliknya apabila tidak ada peningkatan secara positif makabrand image tidak berpengaruh terhadap kepuasan. Ini artinya brand image yang dimiliki Pizza Hut cabang Jember tidak memiliki pengaruh kearah positif maupun negatif terhadap kepuasan konsumen. Maka dari itu, pihak restoran pizza hut cabang Jember perlu mengeksplor, serta meningkatkan brand image agar benar-benar tertanam dibenak konsumen dan dapat memenuhi harapan konsumen.

\section{Simpulan}

Kualitas layanan berpengaruh terhadap kepuasan konsumen. Hal ini dikarenakan layanan yang diberikan dari pihak Pizza Hut cabang Jember sesuai dengan harapan, layanan yang diberikan sudah dari cukup (memuaskan), dengan demikian semakin tinggi kualitas layanan maka kepuasan pelanggan juga semakin meningkat. Harga tidak berpengaruh terhadap kepuasan konsumen. Hal ini dikarenakan harga yang diukur dalampenerimaan dan kewajaran harga tidak sesuai dengan yang ditetapkan oleh pihak restoran Pizza Hut cabang Jember. Maka dari itu perlu dilakukan peninjauan kembali mengenai kebijakan-kebijakan penetapan harga demi terciptanya kepuasan konsumen. Brand image tidak berpengaruh terhadap kepuasan konsumen. Hal ini dikarenakan brand image yang dimiliki Pizza Hut cabang Jember tidak mempunyai pengaruh ke arah positif maupun 
negatif. Pihak restoran pizza hut cabang Jember perlu mengeksplor brand image agar dapat tertanam dibenak konsumen.

\section{Referensi}

Atmaja, Ni Putu. Cempaka Dharmadewi. 2011. Pengaruh Kewajaran Harga, Citra Perusahaan Terhadap Kepuasan dan Loyalitas Pengguna Jasa Penerbangan Domestik Garuda Indonesia di Denpasar. Tesis. Denpasar: Universitas Udayana.

Engel, J.F, Blackwell, Rd, and Miniard, DW. 1990. Perilaku Konsumen Jilid I (Terjemahan Boediono). Jakarta: Bina Rupa Aksara.
Goetsch, D.L \& Davis, S, 1994. Introduction to Total Quality, Quality, Productivity, Competitiveness. Englewood Cliffs: Prentice Hall International Inc.

Kotler Philip. 2005. Manajemen Pemasaran (Terjemahan Hendra Teguh dan Ronny A. Rusli). Jakarta: PT. Prehallindo.

Kotler, P. dan Keller, K, L. 2007. Manajemen Pemasaran (Terjemahan Bejamin Molan) Edisi 12, Jilid 1 dan 2. Jakarta: PT. Indeks.

Melanesia, Herlinda. 2011. Pengaruh Kualitas Pelayanan terhadap Kepuasan Nasabah Bank pada Nasabah PD BPR Bank Sleman di Kabupaten Sleman. Skripsi. Yogyakarta: FE UNY.

Yesenia. 2014. Pengaruh Kualitas layanan dan Produk terhadap Kepuasan serta Loyalitas Pelanggan KFC di Tangerang Selatan. Skripsi. Bogor: Institut Pertanian Bogor. 